\title{
ECO-MOVEMENTT BERBASIS DAKWAH LINGKUNGAN DI YAYASAN DARUL YATAMA WALMASAKIN JEROWARU LOMBOK TIMUR MELALUI MEDIA TEKNOLOGI INFORMATIKA
}

\author{
Suwardji*1, Sukartono $^{1}$, Arifin. A.B ${ }^{1}$, Bambang H.K ${ }^{1}$, Habibi. $\mathbf{P}^{2}$, dan Saeful $\mathbf{I}^{2}$ \\ ${ }^{1}$ Program Studi Ilmu Tanah Fakultas Pertanian Universitas Mataram \\ ${ }^{2}$ Yayasan Darul Yatama Wal Masakin Jerowaru Lombok Timur NTB Indonesia
}

\begin{abstract}
Kata Kunci: Eco movement, Ajaran TGH Sibawai Pelestarian Lingkungan, Kurikulum Lingkungan di Pondok
\end{abstract} Pesantren

\begin{abstract}
Abstrak: Permasalahan kerusakan lahan dan lingkungan merupakan salah satu isu penting yang dihadapi Indonesia dalam agenda pembangunan yang berkelanjutan (SDGs). Pada saat ini telah terjadi kerusakan lahan dan hutan di mana mana di Indonesia termasuk di Provinsi Nusa Tenggara Barat yang belum ada strategi yang efektif dan efisient untuk mengatasinya. Pengabdian Masyarakat dilakukan untuk mendokumentasikan dan memviralkan ajaran Almarhum TGH Sibawaihi dalam membangun gerakan lingkungan (Eco Movement) dalam upaya meningkatkan kesadaran masyarakat akan pentingnya pelestarian lingkungan melalui Yayasan Darul Yatama Wal Masakin (Yadama), Jeruwaru. Belajar dari nilai-nilai dakwah yang telah diajaran oleh Almarhum TGH Sibawaihi akan dikembangkan kurikulum pembelajaran di Yadama melalui inovasi pembelajaran menggunakan teknologi informasi sebagai media untuk menyebarkan nilai-nilai ajaran dan kampanye untuk menjelaskan tentang pentingnya pelestarian terhadap lingkungan yang akan dipublikasikan dalam tiga bahasa pengantar yaitu Bahasa Indonesia, Bahasa Arab dan Bahasa Inggris. Kemudian langkah terakhir adalah dengan menciptakan fondasi sekolah hijau sebagai contoh nyata dalam upaya pelestarian lingkungan di tingkat sekolah melalui integrasi dakwah lingkungan dan kurikulum. Dengan demikian, maka diharapkan dapat tercipta kampanye lingkungan yang lebih luas kepada masyarakat, sehingga lebih banyak orang yang akan sadar akan pentingnya melindungi lingkungan dan mengurangi jumlah manusia yang merusak lingkungannya sendiri. Jurusan Ilmu Tanah berperan dalam rangka transfer ilmu pengetahuan dan teknologi dengan menyediakan tenaga ahli dalam pengelolaan lingkungan hidup kelompok peneliti bidang ilmu dinamika karbon melalui Program Pengabdian Kepada Masyarakat. Program ini juga bertujuan untuk mewujudkan visi dan misi ilmu tanah menuju persaingan global 2025 dengan mengangkat isu-isu global yakni perubahan iklim dan teknologi digital.
\end{abstract}

Korspodensi email: suwardji@unram.ac.id

\section{PENDAHULUAN}

Pulau Lombok yang berada di Provinsi Nusa Tenggara Barat adalah salah satu pulau kecil yang mengalami degradasi lingkungan yang sangat serius akibat perilaku manusia yang tidak memiliki kepedulian terhadap lingkungan disekitarnya. Kerusakan terhadap lingkungan bermula dari kegiatan-kegiatan yang dilakukan oleh manusia, yang lebih mengutamakan keuntungan ekonomi yang sebesar-sebesarnya dengan cara mengeksploitasi lingkungan tanpa mempertimbangkan dampak kerusakan lingkungan sekitarnya yang akan ditimbulkan dari kegiatan tersebut. White Jr. (1967) pernah mengemukakan sebuah tesis bahwa akar historis ekologis yang dihadapi manusia sekarang ini sebenarnya dapat ditemukan pada agama-agama monoteistik. Menurutnya, krisis lingkungan pada dasarnya adalah masalah "ketidakseimbangan" yang dialami karena adanya kegiatan eksploitasi lingkungan yang tidak 
bisa dikendalikan, di samping pertimbangan politik dan ilmiah, ada juga permintaan untuk perspektif teologis sistematis (eco-theology) yang memiliki potensi untuk menarik dimensi spiritual dan psikologis "kesadaran" manusia terhadap komposisi biologis dan fisik lingkungannya.

Dari berbagai penelitian diketahui bahwa factor penyebab kerusakan hutan dan lahan serta terjadinya fenomena perubahan iklim disebabkan oleh ulah dan campur tangan manusia (IPCC, 2007). Bahkan Bidang Planalogi dan Pengamanan Hutan Dinas Kehutanan NTB (Andi Pramaria) dalam Berita Antara tahun 2009 mengatakan bahwa "Pemerintah Provinsi (Pemprov) Nusa Tenggara Barat (NTB) membutuhkan waktu paling sedikit 15 tahun untuk memulihkan kerusakan hutan akibat penggundulan, penebangan liar, perambahan dan pembakaran kawasan hutan. Itu pun kalau program reboisasi dan rehabilitasi kawasan hutan serta upaya pemberantasan praktik pembalakan liar secara terpadu berhasil". Timbulnya masalah lingkungan hidup, menurut Passmore tidak terpisah dari pandangan kosmologis tertentu yang pada kenyataannya telah menumbuhkan sikap eksploitatif terhadap alam. Karena itu, pengembangan etika lingkungan menghendaki adanya perubahan secara fundamental dari pandangan kosmologis yang menumbuhkan sikap eksploitatif terhadap alam kepada pandangan yang menumbuhkan sikap lebih bersahabat dan apresiatif kepada alam.

Pulau Lombok merupakan salah satu pulau yang sebagian besar penduduk yang ada di wilayahnya merupakan penduduk muslim, keberadaan cendikiawan Islam disebut juga dengan Tuan Guru Haji (TGH) yang berperan sebagai seorang fungsionaris dan pendakwah kharismatik yang didengar dan diikuti titahnya oleh khalayak ramai khususnya para jama'ahnya, seseorang dengan memiliki kemampuan "mengajak" yang luar biasa dan bahkan diibaratkan sebagai raja (Datu). Sehingga dalam interaksi sosialnya, Tuan Guru mampu mentransformasi kehidupan masyarakat dalam berbagai bentuk dakwah yang dilakukannya. Tuan Guru mampu melakukan transformasi dalam bidang: pendidikan dan kepesantrenan baik formal maupun informal, sosial dan budaya, ekonomi pemberdayaan kemasyarakatan, politik dan keamanan serta dalam bidang konservasi dan ekonomi lingkungan hidup (Fahrurrazi, 2015). Melihat luasnya peranan Tuan Guru dalam transformasi masyarakat, maka penulis melakukan kajian lebih khusus mengenai dakwah Lingkungan Tuan Guru serta peranannya dalam konservasi alam khususnya di Pulau Lombok.

Salah satu Tuan Guru yaitu TGH. Sibawaihi Mutawalli Yahya Al-kalimi (TGH. Sibawaihi) menjadi role model, subjek penelitian dan menjadikan sosok Beliau sebagai trigger, accelerator, driver dan protector dalam upaya konservasi lingkungan. Dakwah lingkungan yang dilakukan oleh TGH. Sibawaihi telah menghasilkan dampak yang signifikan terhadap perlindungan lingkungan di beberapa tempat di Lombok bagian timur, hal ini juga didasari oleh kharisma dan kapabilitas Beliau (Almagfirulahu) dalam mejalankan dakwahnya sebagai Tuan Guru yang mampu mentransformasi masyarakatnya dan alamnya (Habibi. P., Islam. S., dan Sirajunnasihin. 2018). Namun, Tuan Guru Sibawaihi meninggal pada tahun 2015, oleh karena itu ajaran dan dakwah lingkungan beliau perlu terus dikembangkan serta dilestarikan dengan metode kekinian seperti integrasi ke dalam kurikulum di pondok pesantren dan memanfaatkan media berbasis teknologi informasi (youtube, facebook, blog, website dan instagram) agar dapat dipelajari oleh generasi muda secara berkelanjutan. 
Kegiatan dakwah tersebut sangat penting untuk terus dilanjutkan agar dapat meningkatkan kesadaran masyarakat tentang perlindungan lingkungan dengan menggunakan dakwah dari Tuan Guru Sibawaihi untuk mengintegrasikannya ke dalam kurikulum sekolah dan mengembangkan sekolah hijau. Salah satu Yayasan yang ada di Kecamatan Jerowaru Kabupaten Lombok Timur yaitu Yayasan Darul Yatama Wal Masakin akan dipilih sebagai lokasi untuk melaksanakan kegiatan perlindungan terhadap lingkungan yang diintegrasikan ke kurikulum sekolah yang disertai dengan pengembangan sekolah hijau. Jika kegiatan ini berhasil diharapkan dapat memulihkan lebih banyak kerusakan lingkungan yang ada di Lombok, selain itu diharapkan juga Yayasan lain yang jumlahnya sangat banyak di Lombok dapat mengikuti sistem ini sehingga bisa menyelamatkan planet ini dari degradasi lingkungan yang sudah semakin parah.

Kegiatan ini akan menggunakan dakwah dari TGH Sibawaihi untuk membangun gerakan lingkungan dan kesadaran akan pelestarian lingkungan melalui Yayasan Darul Yatama Wal Masakin, Jeruwaru. Untuk mencapai tujuan ini, kami akan memeriksa dampak dan mengeksplorasi nilai-nilai perilaku perubahan lingkungan, ekonomi, dan sosial dari khotbah TGH Sibawaihi. Selanjutnya akan diterapkan nilai-nilai dampak dari dakwah ke kurikulum pembelajaran di Yayasan Darul Yatama Wal Masakin. Selanjutnya adalah berinovasi dalam pengajaran TGH Sibawaihi menggunakan teknologi informasi sebagai media untuk menyebarkan nilai-nilai khotbah dan kampanye untuk menjelaskan tentang pentingnya pelestarian terhadap lingkungan. Kemudian langkah terakhir adalah dengan menciptakan sekolah hijau sebagai contoh nyata dalam upaya pelestarian lingkungan di tingkat sekolah. Setelah nilai-nilai dari TGH Sibawaihi berbasis lingkungan yang dipraktikkan di Yayasan Darul Yatama Wal Masakin, diharapkan dapat tercipta kampanye lingkungan yang lebih luas kepada masyarakat, sehingga lebih banyak orang yang akan sadar akan pentingnya melindungi lingkungan dan mengurangi jumlah manusia yang merusak lingkungannya sendiri.

\section{Tujuan Kegiatan}

Tujuan dari kegiatan ini adalah sebagai berikut:

1. Untuk mengembangkan dan mengintegrasikan nilai-nilai dakwah islam berbasis lingkungan ke dalam kurikulum sekolah.

2. Untuk menginovasi dakwah lingkungan TGH Sibawaihi Mutawalli menggunakan media dakwah berbasis teknologi informasi untuk membangun kesadaran masyarakat tentang perlindungan lingkungan.

\section{Lokasi dan Waktu kegiatan}

\section{METODE KEGIATAN}

Kegiatan dilaksanakan Di Yayasan Darul Yatama Wal Masakin, Jerowaru Kabupaten Lombok Timur dengan melibatkan pengurus Yayasan, santri/santriwati Madrasah Tsnawiyah (MTs DA) dan Madrasah Aliyah (MA DA); mahasiswa Program Studi Ilmu Tanah Unram dan Alumni Program Studi Ilmu Tanah Unram. Pelaksanaan kegiatan dimulai di awal Mei sampai dengan September 2019. 


\section{Pelaksanaan Kegiatan}

Pelaksanaan kegiatan terdiri dari: 1) focus group discussion, 2) Pelatihan indoor, 3) Pelatihan outdoor, 4) kegiatan pengukuran dengan metode Hairiah., dkk (2016) dan 5) pelatihan pembuatan poster dan media IT untuk dakwah lingkungan.

\section{Focus Group Discussion}

Kegiatan diawali dengan Fokus Group Discusion (FGD) dengan 10 orang anggota guru/pengurus Yayasan yang akan membahas tentang penyusunan kurikulum yang akan menyisipkan materi-materi pelajaran konservasi lingkungan berbasis teknologi informasi (IT) dalam pelatihan ini.

\section{Kegiatan Pelatihan Indoor}

Kegiatan selanjutnya adalah kegiatan pelatihan indoor yang diikuti oleh 10 orang guru/pengurus yayasan dan 50 orang santri dan santriwati. Kegiatan indoor diawali dengan penyampaian materi tentang dampak dari perubahan iklim dan kerusakan lingkungan; filosofi dakwah lingkungan TGH. Sibawaihi; peran serta pondok pesantren dalam adaptasi/mitigasi perubahan iklim; tauladan TGH. Sibawaihi dalam konservasi lingkungan hidup dan antisipasi perubahan iklim; dan Eco-movement berbasis Dakwah IT di pondok pesantren.

\section{Kegiatan Pelatihan Lapangan (outdoor)}

Kegiatan outdoor dilakukan di kawasan lahan aforestrasi/reforestrasi TGH. Sibawaihi seluas 120 ha. Kegiatan yang dilakukan adalah pelatihan estimasi cadangan karbon dari pepohon dan tanah kepada anggota/guru yayasan dan santri/santriwati. Kegiatan lapangan yang dilakukan adalah untuk mengukur cadangan karbon yang ada di lokasi aforestrasi dan reforestrasi yang telah dilakukan oleh TGH. Sibawaihi di Desa Pemongkong, Kecamatan Jerowaru. Lokasi kegiatan lapangan dipusatkan di tiga hutan yang didominasi oleh pohon mahoni (Swietenia Mahagoni), pohon sengon (Albizia chinensis) dan pohon bakau (Rhizophora) yang telah berumur antara 10-15 tahun.

\section{Pelatihan pembuatan Poster dan media IT untuk dakwah lingkungan}

Kegiatan pelatihan dilakukan untuk mengajarkan siswa agar mengerti cara berdakwah dengan memanfaatkan teknologi informasi yang saat ini sudah dimanfaatkan hampir semua orang di dunia ini untuk mengetahui setiap informasi apapun. Pelatihan ini dilakukan bertahap dengan jeda waktu 2 (dua) minggu setiap satu kali pelatihan. Pelatihan yang pertama dilakukan adalah pembuatan Website kemudian pelatihan ke dua adalah pembuatan Youtube, pelatihan ke tiga adalah pembuatan Facebook dan Twitter (telah dilakukan), dan yang terakhir adalah pelatihan pembuatan Brosur dan Poster sebagai media penyebaran informasi kegiatan-kegiatan yang telah dilakukan di Yayasan Darul Yatama Wal Masakin

\section{Metode Pengukuran}

Pengukuran biomasa pohon dilakukan dengan mengukur lingkar/lilit batang atau diameter pohon setinggi dada, yakni setinggi 1,3 m diatas permukaan tanah. Peralatan yang dibutuhkan untuk mengukur biomasa pohon adalah meteran, tongkat kayu/bambu sepanjang 1,3 m untuk memberi tanda pada pohon yang akan diukur diameternya, dan blangko pengamatan. Untuk menentukan lokasi pengamatan ditentukan PLOT KECIL menjadi 2 bagian, dengan memasang tali di bagian tengah sehingga ada 2 bagian PLOT KECIL, masing-masing berukuran $40 \mathrm{~m}$ x $5 \mathrm{~m}$ (untuk ukuran diameter pohon $15 \mathrm{~cm}-95 \mathrm{~cm}$ ) dan $100 \mathrm{~m}$ 
x 20m (untuk ukuran diameter pohon > $95 \mathrm{~cm}$ ). (Hairiah. K., Sari. R.R., Pambudi. S., dan Rahayu. S. 2016).

\section{Solusi yang ditawarkan}

Solusi yang ditawarkan untuk menyelesaikan masalah degradasi lahan yang ada di Pulau Lombok adalah dengan menggunakan khotbah dari TGH Sibawaihi untuk membangun gerakan lingkungan dan kesadaran pelestarian lingkungan yang akan diterapkan pada kurikulum pembelajaran di Yayasan Darul Yatama Wal Masakin yang berbasis konservasi lahan dan teknologi informasi, hal ini dilakukan mengingat sebagian besar penduduk Pulau Lombok adalah sebagian besar muslim yang biasanya sangat patuh terhadap setiap ajaran tuan gurunya.

\section{Target luaran}

Luaran yang dihasilkan dari kegiatan ini adalah Publikasi Ilmiah (jurnal ber-ISSM) yang diterbitkan oleh Lembaga Penelitian dan Pengabdian Universitas Mataram, dan buku panduan konservasi lahan dan teknologi informasi. Sedangkan bagi mitra, luarannya adalah kurikulum di Yayasan Darul Yatama Wal Masakin Jerowaru yang terintegrasi dengan dakwah lingkungan TGH. Sibawaihi. Tedapat media dakwah berbasis Teknologi Informasi berupa website, blog, youtube, facebook dan instagram. Terdapat buku saku, brosure dan flyer tentang dakwah berbasis lingkungan yang diterbitkan oleh Universitas Mataram dan Yayasan Darul Yatama Wal Masakin. Luaran akhir adalah terdapat Sekolah Hijau (Pesantren Hijau) yang pertama kali terdapat di Kabupaten Lombok Timur.

\section{HASIL DAN PEMBAHASAN}

\section{Gambaran Umum Lokasi Kegiatan}

Kegiatan Eco-Movement Berbasis Dakwah Lingkungan di Yayasan Darul Yatama Wal Masakin (Yadama) Jerowaru melalui Media Teknologi Informatika dilaksanakan di Kecamatan Jerowaru, Kabupaten Lombok Timur. Kegiatan ini terdiri dari kegiatan indoor di lingkungan Yadama Desa Jeruworu dan kegiatan outdoor di lahan aforestrasi/reforestrasi TGH. Sibawaihi Mutawalli di Desa Pemongkong yang juga masih terletak di Kecamatan Jerowaru.

Kecamatan Jerowaru merupakan salah satu kecamatan yang berada di kawasan administatif Kabupaten Lombok Timur-NTB dengan luas Kecamatan mencapai 142,78 km² yang terdiri dari 15 desa (lihat gambar. 1). Secara geografis letak kecamatan Jerowaru berada pada ketinggian 13 - 89 meter di atas permukaan laut dan kategorikan sebagai dataran rendah. Kondisi curah hujan di kecamatan Jerowaru adalah berkisar antara $500 \mathrm{~mm} / \mathrm{th}-1200$ $\mathrm{mm} /$ th dengan jumlah hari hujan hanya berkisar antara 47 hari/th - 99 hari/th (Kecamatan Jerowaru dalam Angka, 2018). Dengan kondisi geografis dan iklim seperti ini, maka kecamatan Jerowaru dapat dikategorikan sebagai wilayah agroklimat D4-E4 dengan hanya 34 bulan basah dalam setahun. Sedangkan jumlah peduduk kecamatan Jerowaru adalah 58.069 jiwa dengan mata pencaharian utama berbasis sumberdaya alam berupa pertanian, perikanan dan perkebunan. Namun demikian kondisi ini diperparah dengan terjadinya perubahan iklim. Hal ini ditandai dengan terjadinya perubahan dan pergeseran pola musim penghujan dan musim kemarau ( $3 \%$ pada tahun 2030 ); kenaikan suhu rata-rata yaitu $1-2^{\circ} \mathrm{C}$ pada 10 tahun 
terkahir; kenaikan muka air laut yang dapat mencapai $1 \mathrm{~m}-7 \mathrm{~m}$ sampai pada tahun 2050; serta diperparah dengan meningkatnya pertumbuhan penduduk (6.3 juta penduduk tahun 2050); eksploitasi sumberdaya alam dan alih fungsi sumberdaya alam (Butler et al. 2014).

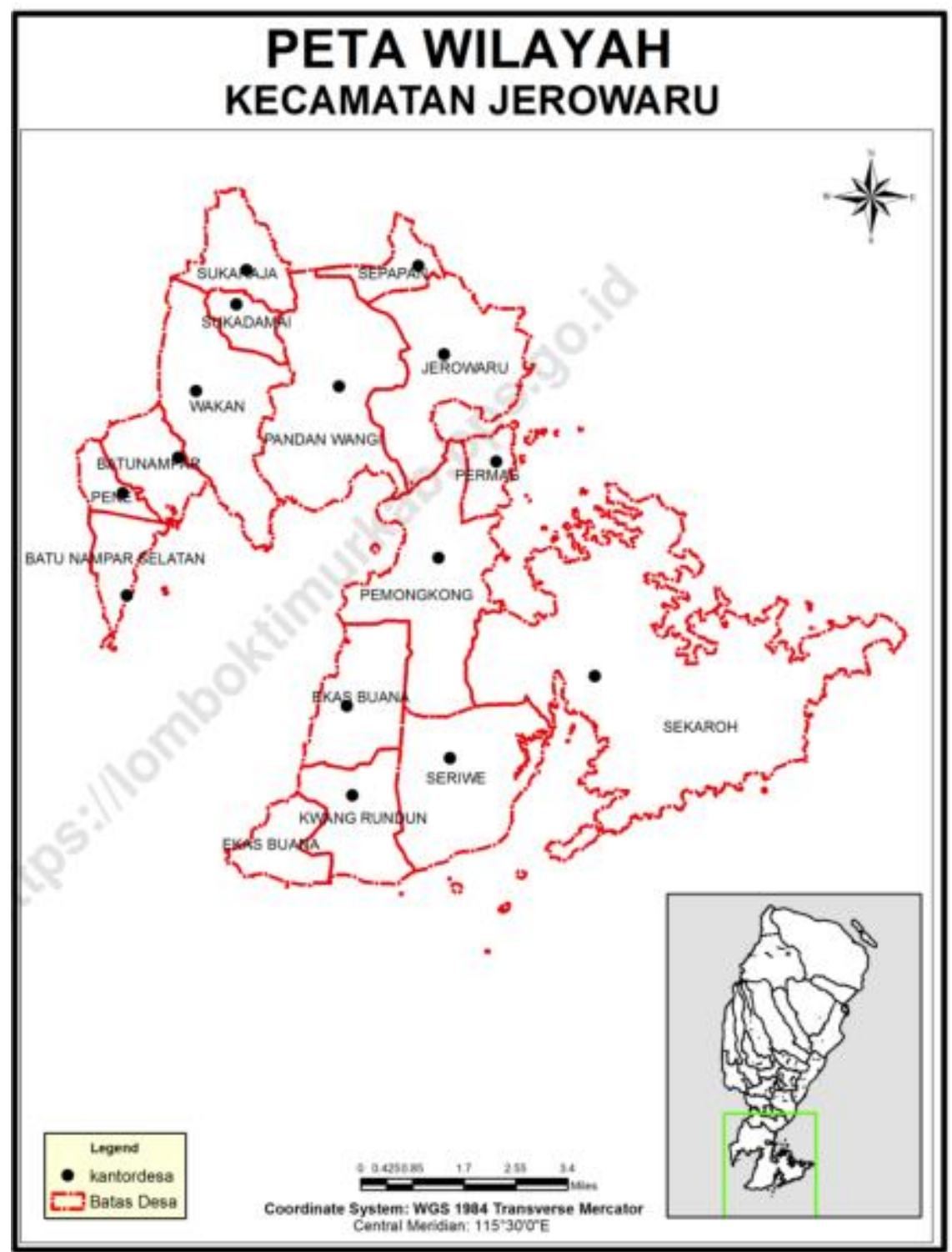

Gambar.1. Peta Lokasi Kegiatan di Kecamatan Jerowaru Kabupaten Lombok Timur

\section{Peserta Kegiatan}

Kegiatan ini diikuti oleh 60 peserta yang terdiri: 1) 10 orang peserta FGD persiapan pelaksanaan kegiatan yaitu guru/pengurus Yadama; 2) 40 orang peserta pelatihan (indoor dan outdoor) yang terdiri dari 15 santri/santriwati MTs DA dan 15 santri/santriwati MA DA serta 10 orang guru pendamping; 3) 2 orang mahasiswa PSIT UNRAM selaku pemateri di lapangan; 4) 3 orang alumni PSIT UNRAM (selaku pemateri di lapangan); dan 5) 4 Dosen Pembina dari Kelompok Peneliti Bidang Ilmu Dinamika Karbon sebagai pemateri dan pembina; serta 6) Ketua Yayasan Yadama sebagai pelindung dan pembina. Nama-nama dan Materi dan peranserta dari peserta dan pemateri dapat dilihat di lampiran. 


\section{Progress Capaian Hasil Kegiatan}

Focus Group Discussion penyusunan materi dan kurikulum pelatihan dan dakwah lingkungan

Kegiatan FGD penyusunan materi pelatihan telah dilaksanakan sejak bulan Mei Agustus 2019 dengan kegiatan di ruangan yaitu untuk;

1) menyusun materi dakwah lingkungan melalui kegiatan Imtaq setiap pagi pukul 07.00 Wita. Kegiatan dakwah lingkungan melalui kegiatan imtaq berupa ceramah pagi oleh santri/santriwati yang disepakati dalam FGD adalah minimal 1 satu kali dalam satu bulan.

2) kegiatan ceramah tersebut dilakukan dalam empat bahasa pengantar yaitu Bahasa Indonesia, Bahasa Arab, Bahasa Inggris dan Bahasa daerah Sasak yang direkam dengan audio dan video yang akan digunakan sebagai bahan kampanye eco-movement dan di upload di Website dan youtube yang telah dibentuk.

3) Kegiatan eco-movement melalui dakwah lingkungan ini telah dimulai sejak tahun ajaran baru bulan September 2019

4) Pembuatan website resmi Yadama yang dibuat oleh Alumni PSIT Unram yaitu Safprada Rizma Huri Haurunnisa. S.P untuk media eco-movement berbasis IT sekaligus sebagai photographer dan video maker. Kegiatan ini diperkaya dengan pembuatan video tanggapan Unram melalui Ketua Jurusan Ilmu Tanah dan KPBI dinamika karbon, serta siswa dan masyarakat dalam upaya eco-movement

\section{Kegiatan pelatihan indoor}

Kegiatan pelatihan indoor telah mulai di lakukan pada tanggal 5 dan 6 September 2019 di Aula Madrasah Aliyah Daarul Aitam Yadama. Kegiatan dalam pelatihan dilakukan dalam 3 bahasa yaitu Bahasa Inggris, Bahasa Arab dan Bahasa Indonesi. Kegiatan ini terdiri:

Tabel 1. Kegiatan Pelatihan Indoor

\begin{tabular}{|l|l|l|l|}
\hline No & Pemateri & Instansi & Materi \\
\hline 1. & $\begin{array}{l}\text { TGH. Saeful Islam, Lc. } \\
\text { M.A }\end{array}$ & $\begin{array}{l}\text { Ketua Yayasan Daarul } \\
\text { Yatama Wal Masakin }\end{array}$ & $\begin{array}{l}\text { Filosofi dakwah lingkungan } \\
\text { TGH. Sibawaihi dan } \\
\text { relefansinya dalam } \\
\text { adaptasi/mitigasi perubahan } \\
\text { iklim }\end{array}$ \\
\hline 2. & Dr. Ir. Sukartono, M.Agr & $\begin{array}{l}\text { Kelompok Peneliti } \\
\text { Bidang Ilmu Dinamika } \\
\text { Karbon PS IT Unram }\end{array}$ & $\begin{array}{l}\text { Pengenalan dampak } \\
\text { perubahan iklim dan } \\
\text { deforestrasi }\end{array}$ \\
\hline 3 & $\begin{array}{l}\text { Ir. L. Arifin Aria Bakti. } \\
\text { M.Sc., Ph.D }\end{array}$ & $\begin{array}{l}\text { Kelompok Peneliti } \\
\text { Bidang Ilmu Dinamika } \\
\text { Karbon PS IT Unram }\end{array}$ & $\begin{array}{l}\text { Pengenalan Adaptasi dan } \\
\text { Mitigasi Perubahan Iklim } \\
\text { dan pengurangan dampak } \\
\text { deforestrasi }\end{array}$ \\
\hline 4 & $\begin{array}{l}\text { Prof. Ir. Suwardji. M. } \\
\text { App. Sc, Ph.D }\end{array}$ & $\begin{array}{l}\text { Kelompok Peneliti } \\
\text { Bidang Ilmu Dinamika } \\
\text { Karbon PS IT Unram }\end{array}$ & $\begin{array}{l}\text { Best practice } \\
\text { Aforestrasi/reforestrasi } \\
\text { TGH. Sibawaihi di Lombok }\end{array}$ \\
\hline
\end{tabular}




\section{Kegiatan pelatihan outdoor}

Kegiatan outdoor dilakukan setelah kegiatan materi di kelas (indoor), dimulai pada tanggal 6-7 September 2019. Kegiatan ini dilaksanakan di lahan aforestrasi/reforestrasi TGH. Sibawaihi di Desa Pemongkong Kecamatan Jerowaru. Kegiatan outdoor ini terdiri dari

Tabel 2 Kegiatan Pelatihan Outdoor

\begin{tabular}{|l|l|l|l|}
\hline No & Pemateri & Instansi & Materi \\
\hline 1. & Putrawan Habibi. SP. MP & $\begin{array}{l}\text { Wakil Ketua Yayasan } \\
\text { Darul Yatama Wal } \\
\text { Masakin dan Alumni } \\
\text { PSIT Unram }\end{array}$ & $\begin{array}{l}\text { Pengukuran Estimasi } \\
\text { Karbon }\end{array}$ \\
\hline 2 & $\begin{array}{l}\text { Ega Rahmawati } \\
\text { (C1B 017 019) }\end{array}$ & Mahasiswa PS IT Unram & $\begin{array}{l}\text { Asisten Pengukuran } \\
\text { Estimasi Cadangan Karbon }\end{array}$ \\
\hline 3 & Husnan Kholid & $\begin{array}{l}\text { Alumni PSIT Unram } \\
\text { Asisten Laboran Ilmu } \\
\text { Tanah }\end{array}$ & Pengukuran Karbon Tanah \\
\hline 4 & $\begin{array}{l}\text { Muhammad Ramdan } \\
\text { Adnan (C1B 016 032) }\end{array}$ & $\begin{array}{l}\text { Mahasiswa PSIT Unram } \\
\text { Alumni PSIT Unram }\end{array}$ & $\begin{array}{l}\text { Asisten Pengukuran Karbon } \\
\text { Tanah }\end{array}$ \\
\hline 5 & $\begin{array}{l}\text { Safprada Rizma Huri } \\
\text { Haurunnisa. S.P }\end{array}$ & $\begin{array}{l}\text { Alumer dan Video } \\
\text { Asisten Laboran Ilmu } \\
\text { Tanah }\end{array}$ \\
\hline
\end{tabular}

\section{Pelatihan pembuatan Poster dan media IT untuk dakwah lingkungan}

Kegiatan ini akan dilaksanakan setelah pengumpulan gambar dan video berakhir yaitu direncanakan pada minggu ke-4 bulan September 2019. Kegiatan ini akan dilakukan secara partisipatif dengan melibatkan seleuruh peserta pada pelatihan ini untuk memilih gambar atau video yang akan digunakan di media dakwah seperti poster, brosur, youtube dan website yadama serta PSIT Unram. Bahasa yang digunakan dalam media dakwah lingkungan dan eco-movement tersebut adalah Bahasa Indonesia, Bahasa Inggris, Bahasa Arab dan Bahasa Daerah Sasak.

\section{Monitoring dan Evaluasi}

Kegiatan M\&E akan dilakukan secara partisipatif yang akan melibatkan KPBI Dinamika Karbon PSIT Unram, Yayasan Yadama serta Santri/santriwati secara periodik setiap bulan dari bulan Oktober 2019 sampai kegiatan ini berakhir bulan Desember 2019. M\&E akan dilakukan dengan menilai banyaknya kegiatan dakwah lingkungan dalam imtaq di MA DA dan MTs DA setiap bulannya, banyaknya tulisan santri/santriwati terkait dakwah lingkungan di kelas, website dan brosure serta persentase guru dan santri/santriwati yang memahami konsep dakwah lingkungan dan ecomovement.

\section{Kesimpulan}

\section{KESIMPULAN DAN SARAN}

1. Yadama telah memiliki media dakwah berbasis lingkungan berupa website www.yadama.or.id

2. Peserta pelatihan telah memahami eco-movement Berbasis Dakwah Lingkungan dan melaksanakannya melalui Media Teknologi informatika 
3. Peserta pelatihan telah memahami cara pengukuran estimasi cadangan karbon di lahan hutan baik yang tersimpan di dalam tanaman maupun yang ada di dalam tanah

4. Program Studi Ilmu Tanah Fakultas Pertanian Unram melalui Kelompok Peneliti Bidang Ilmu Dinamika Karbon telah memiliki hubungan kemitraan yang baik dengan Yadama dalam rangka adaptasi/mitigasi perubahan iklim dan pengurangan dampak deforestrasi

\section{Saran}

1. Mengingat pelatihan ini masih terbatas waktu, maka disarankan untuk dilakukan pendampingan kepada peserta pelatihan yang telah memperoleh pengetahuan baik oleh ahli maupun secara kelembagaan oleh Program Studi Ilmu Ilmu Tanah Fakultas Pertanian.

2. Prospek dan peluang untuk menjalankan Eco-Movement Berbasis Dakwah Lingkungan di Yayasan Darul Yatama Wal Masakin (Yadama) Jerowaru melalui Media Teknologi sangat potensial, sehingga disarankan kepada pihak perguruan tinggi dan pemerintah daerah untuk melanjutkan kegiatan ini ke pondok pesantren lainnya dan menjadikan Yatama sebagai pilot project (starting point) dakwah lingkungan.

Antara NTB. Rabu, 6 Mei 2009 14:16 WIB.

\section{DAFTRA PUSTAKA}

https://mataram.antaranews.com/berita/2698/ntb-butuh-15-tahun-pulihkan-kerusakanhutan Diakses: 11 Desember 2017

Butler, J.R.A., Suadnya, W., Puspadi, K., Sutaryono, Y., Wise, R.M., Skewes, T.D., Kirono, D., Bohensky, E.L., Handayani, T., Habibi, P., Kisman, M., Suharto, I.,Hanartani, , Supartarningsih, S., Ripaldi, A., Fachry, A., Yanuartati, Y., Abbas, G., Duggan, K., Ash, A., 2014b. Framing the application of adaptation pathways for rural livelihoods and global change in Eastern Indonesian islands. Global Environ. Change 28, 368382.

Fahrurrozi Dahlan. 2015. "TUAN GURU: Eksistensi dan Tantangan Peran dalam Transformasi Masyarakat”. Sanabil. Jakarta.

Habibi. P., Islam., S., dan Sirajunnasihin. 2018. DAKWAH LINGKUNGAN TGH SIBAWAIHI: Peranan Tuan Guru Dalam Pelestarian Lingkungan Hidup. Prosiding on 'Prevension Strategy for Food Security, Nutrition and Stunting to Support SDG's Achiement'. Mataram, 13-14 December 2018.

Hairiah. K., Sari. R. R., Pambudi. S., dan Rahayu S. 2016. Pengukuran cadangan karbon untuk masyarakat. Bahan Ajar 2. Bogor, Indonesia: World Agroforestry Centre (ICRAF) SoutheastAsia Regional Program dan Malang, Indonesia: Universitas Brawijaya.

[IPPC] International Panel on Climate Change. 2003. IPPC Guidelines ForNation Greenhouse Inventories : Reference manual IPCC.

Badan Pusat Statistik. 2018. Kecamatan Jerowaru dalam Angka 2018. Katalog BPS 1102001.5203011. Badan Pusat Statistik. Lombok Timur.

White Jr., Lynn (1967) "The Historical Roots of Our Ecologic Crisis", Science, 10 Maret 1967, Vol. 155, N0. 3767 